\title{
ethic@ \\ INDIGNATION, PRACTICAL RATIONALITY AND OUR MORAL LIFE: A GRAMMATICAL INVESTIGATION
}

\author{
JÔNADAS TECHIO ${ }^{1}$ \\ (Universidade Federal do Rio Grande do Sul, Brasil)
}

\begin{abstract}
This paper offers a grammatical investigation of some important aspects of our moral life taking a scene from the movie Mr. Deeds Goes to Town as a test case. The main question I try to answer is whether there are situations in our moral discussions in which the proper and rational attitude is to show disagreement (e.g. by expressing indignation), as opposed to continuing the dialogue. Many philosophers seem committed to a conception of moral reasoning that takes as its end rational agreement among agents; from that perspective, expressing indignation would just amount to an irrational way of trying to get rid of the burdens put upon the agent's shoulders in the context of a moral discussion. Against that widespread view I will defend a Cavellian version of moral perfectionism, which takes rational disagreement as a legitimate (and even productive) outcome of moral arguments. That view, as we shall see, will be predicated upon a distinctive understanding of practical rationality, hence the importance of comparing moral discussion to other forms of rational engagement (e.g., aesthetic, scientific and mathematical).

Key words: Indignation. Practical Rationality. Stanley Cavell. Moral Perfectionism.
\end{abstract}

\section{Introduction}

This paper tries to elucidate some important aspects of our practical rationality by means of grammatical reminders that call attention to particularities of our forms of life as they get expressed and articulated in our ordinary language. The immediate provocation for this paper was a shocking claim made by the Wittgensteinian philosopher Stanley Cavell when commenting a scene from the movie Mr. Deeds Goes to Town ${ }^{2}$. The protagonist of that movie is Longfellow Deeds (Gary Cooper), a simple countryside man who made a living by writing poems for postcards, until he unexpectedly inherited a fortune from a millionaire uncle and moved to his mansion in New York. As one might have expected, Deed's story drew a lot of attention from the local press, which came to nickname him "the Cinderella Man". In the scene that interests me Deeds goes out to dinner at a restaurant whose advertising states that there you can "eat with the literati." Seated at a large table are poets and writers who read 
about Deeds, and when informed of his presence invite him to join the group. Knowing that Deeds writes poems, the intellectuals begin to ask questions about his writing methods, in a condescending and mocking tone. After a while Deeds realizes their true intentions, and leaves the table shouting: "I guess I found out that all famous people aren't big people." Two writers protest trying to prevent his departure, causing Deeds to knock both down by punching them.

Morally speaking, how are we to assess this situation? There seems to be no doubt that the writers acted wrongly, thus deserving some kind of rebuke. But what about Deeds specific reaction - knocking them down; was it legitimate or appropriate? In an abstract and decontextualized analysis of the episode, it is likely that many of us would feel inclined to condemn Deeds attitude; yet for those of us who are familiar with the details of the scene it will be almost inevitable to conclude that at the very least Deeds was right to express his indignation, in one way or another. (I describe here an impression shared by many other viewers who saw the film with me in class.) Of course punching someone is a somewhat radical way to do that, but then again we must remember that this was not Deed's first reaction, and it was raised only after the failed attempt to verbally express his indignation. Leaving aside, for now, the question of acceptable degrees of reaction, the point I would like to explore is this: are there situations in our moral discussions in which the (morally and rationally) proper attitude is to show indignation (say), as opposed to continuing the dialogue?

One of the reasons why this question interests me is that it can help us articulate some reminders about the nature and purpose of a moral discussion, hence about the very nature of our practical rationality. Many philosophers seem committed to a conception of moral reasoning that takes as its end rational agreement among agents. Such a conception, taken literally, excludes (almost by definition) the kind of outcome presented above from the scope of morality; from that perspective, expressing indignation would just amount to an irrational way of trying to get rid of the burdens put upon the agent's shoulders in the context of a moral discussion.

In a passage that alludes to the scene I just described Cavell takes the opposite stance, arguing that "to discover our community a few will have to be punched out, made speechless in their efforts to usurp or devalue the speech of others" (Cavell 2004, 207). In what follows I would like to explore some aspects of Cavell's position 
concerning morality, trying to clarify and defend, if in a limited way, that shocking claim.

\section{What is the point of a moral discussion?}

In Part III of The Claim of Reason (Cavell 1979; hereafter 'CR') Cavell starts an investigation of the nature of moral arguments by citing and commenting the following passage from Plato's Euthyphro:

Socrates: But what kind of disagreement, my friend, causes hatred and anger? Let us look at the matter thus. If you and I were to disagree as to whether one number were more than another, would that make us angry and enemies? Should we not settle such a dispute at once by counting? Euthyphro: Of course.

Socr: And if we were to disagree as to the relative size of two things, we should measure them and put an end to the disagreement at once, should we not?

Euth: Yes.

$[\ldots]$

Socr: Then what is the question which would make us angry and enemies if we disagreed about it, and could not come to a settlement? [...] Is it not the question of the just and unjust, of the honorable and the dishonorable, of the good and the bad? Is it not questions about these matters which make you and me and everyone else quarrel, when we do quarrel, if we differ about them and can reach no satisfactory agreement? (CR 253)

In this excerpt of the dialogue Socrates points to a difference between mathematical and scientific discussions, on the one hand, and moral discussions on the other. The crux of the difference has to do with the conditions of agreement in each case. Thus, if I and my interlocutor are in the midst of a dispute concerning a certain magnitude, for example, and are both competent in the practices of counting and measuring, we can overcome disagreement fairly easily. In most cases, however, disagreement about the best course of action to be taken does not seem so simple to overcome. What is the reason for this difference? Is it due to some peculiar difficulty in becoming morally competent? But exactly what kind of competence would that be? Would it be similar to expertise in mathematics or in some empirical science - a matter 
of acquiring knowledge of (moral) principles, rules or facts, or again about the meaning of (moral) notions?

These issues have divided philosophers throughout history. Socrates himself (at any rate Plato's Socrates) has famously argued that knowledge is the basis of virtue, which implies that in an ideal situation in which two agents were in the same cognitive level regarding the conditions for acting well, rational disagreement would simply not be possible. Closer to our day Moore may be cited as another example of moral cognitivist, and for very similar reasons: according to his "intuitionist" position moral judgments about the "good" (or any other moral term) should (in principle) agree as much as empirical judgments concerning the size of two objects (see Moore 1960).

On the other side of this dispute are the non-cognitivist positions, such as those advocated by the leading exponents of logical positivism in the early 20th century. A. J. Ayer can be taken as a representative. In Language, Truth and Logic (Ayer 1936), he argued that:

[...] ethical philosophy consists simply in saying that ethical concepts are pseudo-concepts and therefore unanalysable. [...] There cannot be such a thing as ethical science, if by ethical science one means the elaboration of a 'true' system of morals. For we have seen that, as ethical judgments are mere expressions of feeling, there can be no way of determining the validity of any ethical system. And, indeed, no sense in asking whether any such system is true. (Ayer 1936, 168)

The dispute between cognitivism and non-cognitivism in ethics and metaethics leads to what Stanley Bates has characterized as an antinomy: cognitivism implies a requirement for agreement among agents that seems absolutely unrealistic; yet non-cognitivism seems completely inconsistent with our moral practices. As Bates summarizes: "if the emotive theory were correct, then a person's use of ethical language would be either an act of bad faith or of alienation, depending on whether he or she did believe that theory or did not" (Bates 2003, 22-3).

Now, the standard "solution" to antinomies is to show that there is a problematic assumption shared by both sides of the dispute, and this is precisely the strategy adopted by Cavell. The assumption in question, not always explicitly formulated, is that "logic and, more particularly, science, provide the models for the 
rationality of argument" (CR 260-261); or, in other words, that a moral argument could only be considered rational if it had a structure similar or analogous to deductive reasoning, "leading from premisses all parties accept, in steps all can follow, to an agreement upon a conclusion which all must accept" (CR 254). Cognitivists like Moore (and before him Plato) accept that assumption and desperately try to show that moral reasoning can meet those requirements, if at the cost of having to postulate a special, intuitive moral faculty; non-cognitivists such as Ayer also tacitly accept that assumption, but because they perceive that ordinary moral arguments fall short of the standard of rationality employed in the context of scientific disputes, they end up excluding morality from the realm of rational assessment, relegating it to the "expression of feelings."

In agreement with Ayer and other non-cognitivists, Cavell thinks it is unrealistic to expect that moral arguments should lead to conclusions that everyone must accept; but disagreement about those conclusions does not need to be taken as an index of a general failure of (practical) rationality, anymore than a failure in ordinary epistemic claims to know would show that knowledge as such is impossible (a point established in parts I and II of CR). Although the hope of reaching agreement is an essential motivation in moral discussions - otherwise we would not be taking seriously the views of our interlocutor - Cavell defends the legitimacy and value of rational disagreement about a course of action. This is possible because, on his view, what distinguishes rationality from irrationality in any domain is not adherence to a specific set of procedures of justification (for example, induction + deduction, or whatever procedures are considered correct in logic, mathematics and other sciences), but rather the commitment to follow the standards considered appropriate in their respective domains, seeking to provide support and justification to what we say or how we act on the basis of that commitment.

One of the distinctive features of scientific rationality is precisely the fact that it is expected that competent users of its patterns of argument must agree in their conclusions; in other words, agreement itself is, in these cases, an index of competence, and hence of rationality. But there are other types of rationality, such as those expressed in aesthetic and moral discussions. In general, it can be said that a discussion is rational to the extent that the judgments made by the interlocutors involved in it are supported by reasons; but nothing, short of a tacit commitment to an intellectualist or scientificist 
conception of rationality forces us to think that the ability to provide reasons should be identified with the ability to apply general (a priori?) principles to particular cases, or with the ability to extract general rules from the experience of multiple instances. Kant himself, who is usually considered a paradigmatic exponent of this intellectualist conception of practical rationality, has noticed the peculiarity of aesthetic judgments, whose operation does not follow inductive nor deductive logic, but by no means excluded them from the scope of rationality, or put into question their claim of objectivity or even universality ${ }^{3}$. The kind of competence that matters in the case of aesthetic judgments is a subject's highly developed ability to detect what might be called "aesthetic saliences", i.e., objective aspects or features of the phenomena at the basis of his or her aesthetic experience, thus anchoring his or her judgment on such aspects. Cavell summarizes this point by saying that "The problem of the critic, as of the artist, is not to discount his subjectivity but to include it; not to overcome it in agreement but to master it in exemplary ways" $(1976,94)$. Thus, an aesthetic judgment can be seen as a critic's invitation for others to share her experience of a work, and it is for this reason that Cavell argues that:

It is essential to making an aesthetic judgment that at some point we be prepared to say in its support: don't you see, don't you hear, don't you dig? The best critic will know the best points. Because if you do not see something, without explanation, then there is nothing further to discuss. $(1976,93)$

That last sentence is critical for my purposes; as Wittgenstein asserted in a different context "explanation must come to an end somewhere" (Wittgenstein 2001, $\S 1$, and knowing when and how to stop in a specific context is also an important indication of a subject's competence in a particular domain of discussion ${ }^{4}$. Anticipating some results, I would like to argue that something similar should also apply to moral arguments, that being the reason why they may end up abruptly, without this being a sign of irrationality. But before I can do that I need to emphasize this important difference between the kinds of agreement expected in the respective fields of aesthetics and science: in the latter agreement is guaranteed precisely by the exclusion of subjectivity, in the former it depends essentially on a controlled or exemplar use of it. It is precisely because of this characteristic that aesthetic and moral arguments, unlike 
scientific ones, will allow their participants to unveil, for themselves and for others, intimate aspects of themselves, articulating and making intelligible the positions they are adopting, and by which they are taking responsibility. Herein lies the interest, but also the risk which is peculiar to aesthetic and moral discussions: they provide an important opportunity for participants to develop their individuality and identity, stimulating an increase in self-knowledge as well as the construction or discovery of a community; but agreement is not always forthcoming, failure is always possible, and it might result in the subject's discovery of her own confusion and opacity, which can in turn lead to humiliation, rejection and ultimately to isolation.

Leaving aside the parallel with aesthetics for a moment, let us try to get clear about what kind of reasons may be morally relevant, that is, what kinds of considerations are legitimate according to the standards of moral discussion. Cavell gives a clue to answer that question in a passage in which he criticizes Charles Stevenson's position, precisely because it does not provide a satisfying criterion for moral legitimacy, considering the use of any statement legitimate that may change the interlocutor's attitudes in a moral discussion. The main problem with this position, according to Cavell, is that its adoption involves treating the interlocutor as a mere object to be manipulated, rather than as a person, "a creature with commitments and cares" (CR 283). As Mulhall clarifies:

for Cavell, a person's commitments are not more or less external to her wants, positions, or modes of conduct, but are rather implications of what she does and who she is. If, for example, someone makes a promise then she is committed to performing a course of action; should she fail to perform that action, then, in order to retain credibility as a moral agent, she must explain why the circumstances in which she found herself justified her failure to honour that commitment, why she could not have given advance warning to those relying upon her promise, and so on. (Mulhall 1994, 37)

As an agent cannot simply fail to take seriously his own previous commitments, on pain of being exiled from the moral realm, neither can a person be considered morally responsible who seeks to criticize the behavior of another agent without taking into account (or at least without making an effort to try to understand) the commitments and concerns of that agent. In other words, (competent) moral 
evaluations should not focus excessively (let alone exclusively) on the set of actions and choices of a subject at a given time, but should be made against the background of his previous cares and commitments. The mistake to be avoided is taking the identity of a moral being as a mere sum of (right or wrong) "discrete" actions or choices, and the alternative is to focus on their narrative identity, which, although subject to continual change, is usually far from being completely unstable ${ }^{5}$.

If the description of the logic of moral reasoning presented so far is in the right tracks, then we can conclude that moral arguments will be competent to the extent in which they exhibit an appeal to at least two kinds of reasons, which Cavell dubs, respectively, "basis of care" and "grounds of commitment": the first "provides whatever sense there will be in your confronting someone with what he 'ought' to do", the second "grounds what you say 'must' be done in that person's commitments, both his explicit undertakings and the implications of what he does and where he is, for which he is responsible" (CR 325). An important implication of this analysis, which I would like to emphasize, is that if an interlocutor has challenged a certain behavior of mine by appealing to the sort of reasons we have just described - taking into account my "cares and commitments" - then I cannot simply ignore her challenge on pain of manifesting incompetence and, to that extent, irrationality in a moral context. But that does not mean that a competent challenge will always demand my acceptance of it; I can recognize the relevance of the "basis of care" and the "grounds of commitment" presented by my interlocutor without agreeing with the weight or importance she gives to them.

Here is another important difference between moral and scientific discussions: the latter seek to determine whether a certain cognitive claim is to be accepted based on the evidence presented by someone, as well as on her general competence in the field; but in the case of a moral discussion what really matters is to determine whether we can understand and respect (but not necessarily agree with) positions or attitudes assumed by others. Instead of the adequacy of a claim to certain universal and impersonally established principles, moral reasoning is constructed in terms of responsiveness between agents, and puts to the test the quality and, ultimately, the very possibility of creating or maintaining a relationship based on shared cares and commitments. This difference is presented by Cavell as follows: 
Questioning a claim to knowledge takes the form of asking "How do you know?" or "Why do you believe that?", and assessing the claim is, we could say, a matter of assessing whether your position [...] [is] adequate to the claim. Questioning a claim to moral rightness [...] takes the form of asking "Why are you doing that?", "How can you do that?", "What are you doing?", "Have you really considered what you're saying?", "Do you know what this means?"; and assessing the claim is [...] to determine what your position is, and to challenge the position itself [...]. The point of the assessment is not to determine whether it is adequate [...] [but] to determine [...] what position you are taking responsibility for - and whether it is one I can respect. What is at stake in such discussions is not, or not exactly, whether you know our world, but whether, or to what extent, we are to live in the same moral universe. What is at stake [...] is not the validity of morality as a whole, but the nature or quality of our relationship to one another. (CR 268)

The ability to maintain a moral relationship depends essentially on the cares and commitments at stake - and we will be willing to require or to tolerate more or less from our interlocutors according to the weight given by each of us to those factors. Let us see how this works by analyzing a concrete case of moral discussion imagined by Cavell (see CR 266):

A: I've Decided against offering him the job.

B: But he's counting on it. You most explicitly promised it to him.

A: I know, but it has suddenly become very inconvenient to have him around, and there is someone else really better qualified anyway.

B: If you do this to him, I'll never speak to you again.

A: Don't make such an issue out of it. I'll see that he gets a job, and I'll give him some money to see him through.

B: Goodbye.

In this little dialogue $\mathrm{B}$ criticizes $\mathrm{A}$ 's intention of breaking a promise made to a third party. Note that B is not evaluating whether A's attitude is right or wrong, good or bad as such (it is not a matter of determining, for example, whether it expresses a "universally valid principle", such as “one shall keep one's promises, no matter what"); what is at stake is whether A really is in a position to assume that attitude responsibly, given her own previous commitments. In summary, B is accusing $\mathrm{A}$ of being a hypocrite, and, given that in her reply A does nothing more than confirm that 
accusation, $\mathrm{B}$ ends up concluding that they live in a different moral universe, and that she may have been misled about A up to now. It is in this sense that one can say (as does Mulhall) that "moral discussion is an arena for the revelation of one self to another" (Mulhall 1994: 41).

\section{Perfectionism and the limits of morality}

In the dialogue just analyzed we were presented to a momentary disagreement between agents that could, at least in principle, find new grounds to carry on the discussion (one should not overlook the importance of time and patience in mundane affairs). But there are cases where a conflict could end up putting morality as a whole into question, and that, according to Cavell, simply indicates that morality should be seen as limited in its potential, leaving room for ideas like the "salvation of the self through the repudiation of morality" (CR 269), which, as we shall see, already points to the theme of "moral perfectionism" which will be explored more systematically in Cavell's recent output. Here's the crucial passage in The Claim of Reason supporting that suggestion:

Morality must leave itself open to repudiation; it provides one possibility of settling conflict, a way of encompassing conflict which allows the continuance of personal relationships against the hard and apparently inevitable fact of misunderstanding, mutually incompatible wishes, commitments, loyalties, interests and needs [...]. Other ways of settling or encompassing conflict are provided by politics, religion, love and forgiveness, rebellion, and withdrawal. Morality is a valuable way because the others are so often inaccessible or brutal; but it is not everything; it provides a door through which someone, alienated or in danger of alienation from another through his action, can return by the offering and the acceptance of explanation, excuses and justifications, or by the respect one human being will show another who sees and can accept the responsibility for a position which he himself would not adopt. We do not have to agree with one another in order to live in the same moral world, but we do have to know and respect one another's differences. (CR 269) 
Recall that, according to our previous analysis, the hallmark of moral reasoning is that it must meet the requirement of intelligibility ${ }^{6}$. But, as Cavell suggests in another context, that still leaves many questions unanswered, such as, for example:

whether there are limits to the obligation to be intelligible, whether everyone isn't entitled to a certain obscurity or sense of confusion, and at some times more than others. Maybe there isn't always something to say; and there is the question of what one is to do about persisting disagreement, how far you must go in trying to resolve it [...] (Cavell 2004, 25)

At this juncture I feel compelled to exhort: let's be honest - how far are we willing to go on a moral discussion characterized by "persisting disagreement"? Indefinitely? I don't think so. But what does this show? That we are not perfect and, particularly, that we are not completely rational? But why exactly would it always be irrational to give up a discussion if we are convinced (rationally, let me add) that it will not lead anywhere further, that the possibility of providing additional reasons has ran out (at least momentarily)? - Returning to the case of Mr. Deeds, described in the begginning of this paper: would he have been wiser if he tried to rationally persuade those literati that, say, they should not go around making fun of people? Or would that just sound pathetic? ${ }^{7}$

Commenting on these issues in more general terms, Cavell claims the following:

[...] hatred and anger are not essentially irrational, but may clearly be called for. To live a moral life should not require that we become Socrateses or Buddhas or Christs, all but unprovokable. But we are asked to make even justified anger and hatred intelligible, and to be responsible for their expression in our lives, and sometimes, not always and everywhere, to put them aside. (Cavell 2004, 25-6)

I want to emphasize three points from this passage: first, it suggests that it is possible to distinguish between justified and unjustified anger and hatred, and, second, it also states that even in those cases where those feelings (and their consequences) are justified, we are still required to make them intelligible and (to that extent) take responsibility for them. Clearly we are not here thinking of those cases in which we 
regret an assault of anger immediately after the fact; the interesting case is that in which, all things considered, we remain convinced, at least partially, that our attitude was appropriate to the situation (think of B after saying goodbye to her friend A). I say "partially" because in real life (but also in good literature and in good movies!) things are not so simple, and we are not always clear about our own motivations. That's why and here's the third point I want to emphasize - Cavell closes the passage calling attention to the fact that, at least on some occasions, the demand for intelligibility will make us reconsider the situation, "putting aside" our first reaction.

Consider again the abrupt conclusion of the discussion between Deeds and the literati, due to the former's feeling of indignation. In that case, to whom exactly would Deeds own justifications and explanations? It does not seem plausible to think that he owns them to the literati themselves - at least not immediately. That discussion is momentarily closed, and the best one can hope is that, after both parties had time to coolly reconsider their attitudes and motivations, against the background of their cares and commitments, a plea for excuses can be made, allowing them to resume their relationship ${ }^{8}$. But what are the conditions for such a reconsideration in the first person? If the agent is confused, would it really be possible for her to find intelligibility on her own, providing reasons and explanations to herself? It is because of this difficulty that many philosophers have emphasized the role of the figure of a friend in the pursuit of intelligibility and moral education. But in no other moral theory that role receives as much attention as in perfectionism, as understood by Cavell.

Cavell describes perfectionism as "a dimension or tradition of the moral life that spans the course of Western thought and concerns what used to be called the state of one's soul, a dimension that places tremendous burdens on personal relationships and on the possibility or necessity of the transforming of oneself and of one's society" (Cavell 1990, 2). This dimension is expressed in a rather diverse set of texts, including canons of philosophical tradition - authors such as Plato, Aristotle, Locke, Kant, Mill, Nietzsche and Rawls - literature - Shakespeare, Ibsen, George Bernard Shaw - and also "texts by writers not usually considered by professional philosophers to be moral thinkers" - particularly Emerson and Freud (see Cavell 2004, ix) ${ }^{9}$. Such texts are seen as variations on the theme of "human nature as divided or double", hanging between the acceptance of the present state of the world as the stage of our activities and prospects and the desire for its reform or transfiguration (see Cavell 2004, 1-2). Yet the kind of 
perfectionism that interests Cavell is to be distinguished from what he calls a "religious perfectionism", committed to the idea of a final or ultimate human perfection.

In my experience when trying to introduce the idea of perfectionism it has been common to notice an immediate aversion caused by the use of that very term, precisely because of this connotation of "ultimate perfection" that it more or less inevitably carries. Add to this a certain (superficial) reading of Nietzsche and Emerson as "elitist" and "undemocratic" philosophers and the stage is set for this position not to be taken seriously by some interlocutors. It is not my intention here to try to undo these misunderstandings ${ }^{10}$. Instead, I shall only indicate that an alternative reading is possible. Cavell himself denounces an elitist perfectionism, centrally concerned with the "individual cultivation" as "debased" $(2004,18)$. In its place he proposes a collective, democratic and continual search for what Emerson describes as "an unattained but attainable self" ${ }^{11}$ : "a self that is always and never ours - a step that turns us not from bad to good, or wrong to right, but from confusion and constriction toward self-knowledge and sociability" $(2004,13)$. In addressing these issues Cavell proposes a very instructive contrast with Plato:

Plato's idea of a path to one goal (the one sought by the sage) does not exactly fit Emerson's idea of how to live. In both, the idea of philosophy as a way of life plays a role in assessing your life now, but Emerson is less interested in holding up the life of the sage as a model for ours than in reminding us that the power of questioning our lives, in, say, our judgment of what we call their necessities, and their rights and goods, is within the scope of every human being (of those, at any rate, free to talk about their lives and to modify them). (Cavell 2004, 13)

What would Emerson suggest, then, in place of Plato's sage? The answer to this question brings us back to the point raised earlier - namely the role of the friend, that exemplar or model of an "unattained but attainable self". If I'm confused and have troubles making my own actions and attitudes transparent and understandable, it is difficult to take the next step toward that ideal, the "further self", so I need some kind of external attraction. A friend may provide such an attraction, as she can reveal our own flaws - make ourselves confront our confusion - in a way that will not generate much resistance, given her specific moral stance in relation to our "cares and commitments." 
The friend does not confront me providing impersonal reasons, but from a position which she occupies in relation to those commitments. Now if some willingness to understand and to be understood is necessary for moral argument, then it is easy to see how a context of friendship and mutual respect is particularly suitable for that purpose. It is especially in this kind of context that we can move forward in our moral education - an education which, according to Cavell, is not intended primarily "to provide an increase of learning but a transformation of existence" (Cavell 2005, 325) ${ }^{\mathbf{1 2}}$.

But to say that a context of friendship is particularly suited to advance our moral education is not to say that we can only move forward in such contexts. As a friend warned, "enemies and strangers can also teach us something about the morality of our conduct. We learn definitive lessons listening to what we do not want to, from those we barely know"13. Certainly; however, it seems to me that this will only be possible in cases in which even our enemies or strangers share at least some of our own commitments and cares. ${ }^{14}$ The only scenario which is being excluded as conducive to the moral discussion is one where the interlocutors, in Cavell's words, live in completely distinct moral worlds. Having this in mind, consider one last time what happened between Deeds and the literati: these have not shown any genuine interest in Deed's cares and commitments, treating them from the beginning as pointless or laughable (remember how they laughed at the fact that Deeds was a postcard poet, for example ${ }^{15}$ ).Yet Deeds came from an opposite perspective, of admiration and respect, hence his painful frustration realizing what was truly going on. He was humiliated and found himself isolated, and so decided to do the same with the literati, restoring the terms of their relationship. By doing this, I believe he provided a great opportunity for the literati to rethink their attitudes and learn from their mistakes. He himself learned an important lesson: "all famous people aren't big people". Confrontational moments like this are in fact crucial to our moral education. But, as I hope I have indicated, this finding does not seem to contradict the Cavellian point about the importance of conversation for mutual revelation of agents - on the contrary, I believe it is reinforced.

\section{Epilogue: cinema and perfectionism}

Throughout this text I kept returning to a single scene from a Hollywood comedy of the 1930s. This procedure is familiar to Cavell's readers, especially of those 
works explicitly concerned with the subject of perfectionism. The conviction behind this procedure is that the themes, motifs and concerns expressed in some films particularly those which Cavell groups under the genres of "remarriage comedies" and "melodramas of the unknown woman" - justify their inclusion in that same tradition of Western thought that "concerns what used to be called the state of one's soul"16. Because these films are themselves "perfectionist studies" in which the protagonists engage in a journey toward an "further self", marked by countless conversations with friends ${ }^{17}$ - figures that "may occur as the goal the journey but also as its instigation and accompaniment" (Cavell 2004, 27) ${ }^{18}$ - they serve as:

a small laboratory for studying moral conversation not as the attempt to persuade someone to a course of action, or as the evaluation of a social institution, but of something I think sometimes as prior an preparatory to these familiar goals of moral reasoning, sometimes as subsequent and supplementary, namely the responsiveness to and examination of one soul by another. It is prior because it provides us with studies of the standing a moral agent claims in confronting another with his/her judgment; it is subsequent because it provides the space for evaluating the moral framework within which you are reasoning. [...] Perfectionism may be said to concentrate itself on the demand to make ourselves, and to become, intelligible to one another.

And I suppose no outlook would cont as moral which did not make place for such a demand (Cavell 2005, 339) ${ }^{\mathbf{1 9}}$.

The films with which Cavell is concerned portray the protagonists's effort (but not necessarily their success) to become better people, choosing a better way of $\operatorname{life}^{20}$. By insisting on the relevance of including these films in the set of texts that explore perfectionist themes Cavell does not want to give the impression that "philosophy left to itself requires compensation by the revelations within the medium of film" (Cavell 2004, 5-6), but, on the contrary, he wants to indicate that these films can be thought of as

differently configuring intellectual and emotional avenues that philosophy is already in exploration of, but which, perhaps, it has cause sometimes to turn from prematurely, particularly in its forms since its professionalization, or academization [...]. The implied claim is that film, the latest of the great arts, shows philosophy to be the often invisible accompaniment of the ordinary 
lives that film is so apt to capture (even, perhaps particularly, when the lives depicted are historical or elevated or comic or hunted or haunted). (Cavell 2004, 5-6)

With these two ideas - namely, that we should resist the temptation of abandoning prematurely the complexities of our ordinary lives, and that films are particularly suitable for capturing those complexities - I think I have reached an appropriate point to stop, hopefully allowing for a continuation of our conversation about the nature of morality. 


\section{Notes}

${ }^{1}$ Professor of Philosophy at the Federal University of Rio Grande do Sul (UFRGS), Porto Alegre, R.S., Brazil. e-mail: jonadas.techio@ufrgs.br.

Thanks to Eduardo Vicentini de Medeiros, Flavio Williges, Nykolas Friedrich von Peters Correia Motta, Paulo Faria and Priscilla Tesch Spinelli as well as to the participants in the Stakes of Speech Summer School at Lehigh University for comments earlier versions of this text.

${ }^{2}$ Frank Capra, USA / Columbia, 1936.

${ }^{3}$ See Kant 2007, especially $\S \S 7-8$ and $\S 19$.

${ }^{4}$ It might go without saying, but clearly competence in mathematics and other sciences shares the same feature.

5 Thanks to Flavio Williges for suggesting this formulation. I register a connection between this discussion and the treatment of stability in our moral practices provided by Peg O'Connor in her book Morality and Our Complicated Form of Life (O'Connor 2008). The point that interests me particularly in that work is a critique of a certain "philosophical image" according to which only foundations could provide stability to our moral practices. The alternative she puts forward is as simple in its formulation as it is fruitful in its consequences - namely, to try and change the dominant metaphor for dealing with normativity in metaethics, so that instead of seeking to locate (and/or replace) its foundations, one should try to understand (and/or change) the conditions allowing stability to be created and maintained among numerous aspects of our practices (linguistic and otherwise). Stability, as O'Connor defines it, 'is a matter of balanced relationships among a whole set of factors, and [it] comes with a constant recognition of limitations and location' (ibid., p. 14). That notion has its original home in architecture, where one of the main aims is to combine heterogeneous elements so as to achieve a balance between immobility and flexibility: 'Concrete can only bend so much, steel can only hold so much weight, glass can only take so much pressure' (ibid.); by combining those materials and properties, an architect can create a structure which stands up due to both balance and tension: 'just consider the importance of movement in a tall building or bridge' (ibid.). Now, according to O'Connor, something analogous holds of normativity in general-be it ethical or linguistic.

${ }^{6}$ An indication of the centrality of this feature is the fact that it permeates the most different traditional conceptions of morality - for example, the utilitarian "calculation of consequences" or the Kantian "interpretation of motives and principles" (see Cavell 2004, 25).

${ }^{7}$ Here's another injunction made by Wittgenstein for different purposes: "Do not think, but look!" (2001, $\S 66)$.

${ }^{8}$ I register for possible future treatment that the dynamics of the attempts at reconciliation and the importance of maintaining a moral community are themes dear to Cavell. The key concept employed in the analysis of this dynamic, inherited from J.L. Austin, is that of "elaboratives" - "those excuses, explanations, justifications [...] which make up the bulk of moral defense" (CR 296, see also Cavell 1976, 26-30 and CR 324-5).

${ }^{9}$ Not to mention films "from the so-called Golden Age of Hollywood talkie" (ibid.). More about the relationship between cinema and perfectionism in the Epilogue.

${ }^{10}$ James Conant sought to do this with respect to Nietzsche's text in (Conant 2000, 181-257), and Cavell has been trying to do the same in relation to Nietzsche and Emerson in several recent works, particularly (Cavell 1990).

11 The sentence comes from the essay "History" (Essays, First Series [1841]), available online here: http://www.vcu.edu/engweb/transcendentalism/authors/emerson/essays/history.html [accessed 08/09/2016] 
12 The passage continues addressing the importance of "marriage": "those who cannot inspire one another to such an education are not married; they do not have the right interest for one another." Unfortunately this is an issue that I could not address in this text.

${ }^{13}$ I am indebted to Eduardo Vicentini de Medeiros for this consideration, made in an e-mail exchange.

${ }^{14}$ Recall the great (albeit limited) mutual respect that arch-enemies invariably show in fiction.

${ }^{15}$ Thanks to Nykolas Friedrich Correia Motta for calling my attention to this point..

${ }^{16}$ Passage quoted in full above.

${ }^{17}$ Cavell describes them as "films whose conversations are among the glories of world cinema" (Cavell 2005, 338)

${ }^{18}$ Still on this point: "The presence of friendship in the films we will consider (including the sometimes drastic lack of this relation in the melodramas) is of the most specific importance in establishing them as perfectionist narratives." (Cavell 2004, 27).

${ }^{19}$ Italics added.

${ }^{20}$ In the specific case of "remarriage comedies" this quest is presented as an alternative to the threat of "moral cynicism": the temptation to give up on a life more coherent and admirable than seems affordable after the compromises of adulthood come to obscure the promise and the dreams of youth. The fact that the principal pair in these comedies is somewhat older than the young pairs of classic comedy provides a context in which certain ways of fulfilling earlier dreams have collapsed and a new regime must be formed to which consent can now, on reflection, be won, or wagered. (Cavell 2004, 23-24) 


\section{References}

Ayer, A. J. 1936. London: Victor Gollancz Ltd.

Bates, S. 2003. "Stanley Cavell and Ethics". In: Stanley Cavell, edited by Eldridge, R. New York: Cambridge UP.

Cavell, S. 1976. Must We Mean What We Say? A Book of Essays. Cambridge: Cambridge University Press.

Cavell, S. 1979. The Claim of Reason: Wittgenstein, Skepticism, Morality and Tragedy. Oxford: Oxford UP.

Cavell, S. 1990. Conditions Handsome and Unhandsome: The Constitution of Emersonian Perfectionism. Chicago: Univ. of Chicago Press.

Cavell, S. 2004. Cities of Words: Pedagogical Letters on a Register of the Moral Life. Cambridge (MA) \& London: Harvard University Press, 2004.

Cavell, S. 2005. Cavell on Film. Albany: SUNY.

Conant, J. 2000. "Nietzsche's Perfectionism: A Reading of Schopenhauer as Educator". In Nietzsche's Postmoralism, edited by Schacht, R. Cambridge UP.

Eldridge, R. 2003. Stanley Cavell. New York: Cambridge UP.

Kant, I. 2007. Critique of Judgment. Walker, N. and Meredith, C. (Tr.). Oxford: Oxford University Press.

Moore, G. E. 1960. Principia Ethica. Cambridge: Cambridge University Press.

Mulhall, S. 1994. Stanley Cavell: Philosophy's recounting of the Ordinary. Oxford: Oxford University Press.

O'Connor, P. 2008. Morality and Our Complicated Form of Life: Feminist Wittgensteinian Metaethics. New York: Pennsylvania State University Press.

Wittgenstein, L. 2001. Philosophical Investigations. 3rd Ed G. E. M. Anscombe (Tr \& Ed.). Oxford: Blackwell Publishing. 